\title{
Heterogeneidad ocupacional del empleo femenino en la ciudad de México, 1970*
}

\author{
Jane R. Rubim-Kurtzman**
}

Este artículo investiga las características de las mujeres trabajadoras y las de sus hogares que determinan la condición salarial, o la distribución en categorías asalariadas y no asalariadas. El estudio se enfoca sobre las mujeres de la ciudad de México en 1970, una época de crecimiento económico relativo. La presente investigación forma parte de un estudio más amplio que analiza el empleo femenino en México durante periodos de prosperidad y adversidad.

Para probar el argumento que establece que aunado a los factores de la demanda de trabajo, los determinantes de la condición salarial de las mujeres también están influidos por limitaciones individuales y familiares tales como: edad, escolaridad, estado civil, condición migratoria, tamaño de la familia, género del jefe del hogar, estructura del mismo, número de miembros del hogar que trabajan, y la presencia de hijos pequeños, empleadas domésticas y personas mayores en el hogar el análisis utiliza la regresión logística. Los resultados indican que las mujeres que tienen responsabilidades domésticas más grandes tienen mayor probabilidad de ser no asalariadas. Los principales determinantes individuales y familiares de la condición salarial son: el estado civil, la edad, la escolaridad y dos variables que se aproximan al concepto de la disponibilidad de personas en el hogar que puedan ocuparse en ei cuidado de los dependientes, es decir, la presencia de empleadas domésticas y de personas mayores en el hogar.

\section{Introducción}

La evidencia de la persistencia y expansión de diversos tipos de empleo no-asalariado ha venido progresando paralelamente con el crecimiento del empleo manufacturero e industrial (pREALC, 1982; Portes y Benton, 1984; Castells y Portes, 1986) desmintiendo las expectativas teóricas acerca de que el empleo no asalariado en

* Este estudio forma parte de la investigación para mi tesis de doctorado sobre los cambios en los determinantes del empleo femenino en la ciudad de México durante los años setenta. La investigación se realizó con fondos de la Fundación Interamericana y el Population Council. El Colegio de México y la Universidad de California en Los Ángeles proporcionaron el apoyo institucional. Deseo agradecer a las profesoras Brígida García y lulieta Quilodrán sus comentarios críticos a las primeras versiones de este artículo.

** The Rand Corporation, Santa Mónica, California. 
las áreas urbanas pasaría a ser una parte cada vez más insignificante del empleo total durante el transcurso del desarrollo económico (Lewis, 1959). En la ciudad de México, el crecimiento reciente del empleo no-asalariado, especialmente entre las mujeres, se asocia con la crisis económica de los años ochenta (Oliveira, 1989). Este estudio investiga las características individuales y familiares de las mujeres que trabajan y que determinan su condición salarial, o su distribución en las categorías asalariadas y no asalariadas en 1970, una época de relativa prosperidad económica. El análisis permite establecer el escenario para el estudio subsecuente del empleo no asalariado entre las mujeres en la ciudad de México durante los años setenta y ochenta, considerado como un periodo de creciente adversidad económica.

Los debates acerca de la relación entre el desarrollo económico y la subutilización del trabajo en América Latina se enfocan sobre la heterogeneidad de la estructura ocupacional o la coexistencia de múltiples modos de producción. La heterogeneidad ocupacional es una característica central del mercado de trabajo urbano en México. Entre 1940 y 1980, por ejemplo, el empleo en el sector moderno no-agrícola creció a una tasa anual de $4.6 \%$ y la proporción de la población económicamente activa ocupada en las manufacturas se incrementó de 12.4 en 1950 a $17.6 \%$ en 1980 ípREALC, 1981; Rendón y Salas, 1987). A pesar de ello, la proporción de la población urbana económicamente activa ocupada en el llamado sector informal ${ }^{1}$ se incrementó también, de 13 a $22 \%$ (Portes y Benton, 1984). Este complejo panorama del empleo industrial y la creciente subutilización del trabajo plantean el reto a los investigadores para explicar por qué y bajo qué condiciones coexisten y proliferan múltiples modos de producción.

\section{Datos y métodos}

El análisis se basó en una submuestra de 1032 mujeres trabajadoras de entre 20 a 49 años, cuyos datos se tomaron de la Encuesta de Migración Interna, Estructura Ocupacional y Movilidad Social de 1970, una muestra probabilística estratificada de hogares del Área Metropolitana de la ciudad de México. Las mujeres que perciben un salario por su trabajo se distinguen de las que se desempeñan en modos de producción alternativas, es decir, en ocupaciones no asalariadas. Las trabajadoras no asalariadas se definen

\footnotetext{
${ }^{1}$ El sector informal se define como la suma de trabajadores por cuenta propia, trabajadores familiares no remunerados y empleados domésticos.
} 
como autoempleadas o trabajadoras por su cuenta, y las trabajadoras familiares no remuneradas. ${ }^{2}$ Al momento de la encuesta, $86 \%$ de las mujeres trabajadoras eran asalariadas. De $14 \%$ de las mujeres que eran no asalariadas, 9.6 eran trabajadoras por cuenta propia; $4.4 \%$ restante eran trabajadoras familiares no remuneradas.

Empiezo el análisis comparando la distribución de las trabajadoras asalariadas versus las no asalariadas por sector económico, ocupación e ingreso. Después de discutir las relaciones bivariadas, utilizo la regresión logística para especificar modelos competitivos cuyo resultado es el logaritmo de una razón del empleo asalariado denominada "momio". La variable dependiente es la condición salarial (WAGESTAT), una variable categórica codificada de la siguiente forma: $\mathbf{1}$ = asalariada, $0=$ no asalariada. Las variables independientes son: edad, escolaridad, condición migratoria, estado civil, tamaño de la familia, género del jefe del hogar, número de trabajadores adicionales en el hogar, estructura del hogar, la presencia en el hogar de niños pequeños, empleadas domésticas y personas mayores. Examino las diferencias entre las categorías de la condición salarial y termino considerando a las vendedoras ambulantes y al servicio doméstico como ocupaciones de interés teórico especial.

\section{El sector informal}

Un grupo importante de trabajos sobre la heterogeneidad ocupacional de las mujeres pertenece a la línea de estudios sobre el sector informal. El Programa Regional de Empleo para América Latina y el Caribe (PREALC), el principal promotor de la investigación sobre el sector informal en América Latina, enfatiza la naturaleza del proceso de desarrollo, el fracaso de los sectores modernos de la economía urbana para absorber la fuerza de trabajo a una tasa

${ }^{2}$ Esta definición continúa la tradición establecida por investigadores mexicanos (García, Muñoz y Oliveira, 1982; García, 1988). En años recientes el resurgimiento del sistema de subcontratación y la compatibilidad entre el trabajo industrial a domicilio y el trabajo doméstico no remunerado en la ciudad de México ha venido adquiriendo una atención creciente. Benería y Roldán (1987) documentan el trabajo industrial a domicilio en diversas industrias, especialmente la de textiles y de electrónica. Se puede argumentar si los trabajadores industriales a domicilio son asalariados o no asalariados y, en realidad, ambas posiciones son persuasivas. Se reconoce que la diferencia en la definición de los trabajadores industriales a domicilio influiría sobre los resultados. Desafortunadamente, los datos no proporcionan información por separado sobre el trabajo industrial a domicilio como una categoría de trabajo. 
adecuada al crecimiento de la población y las características de los trabajadores. ${ }^{3}$ El enfoque del PREALC, que conceptualiza a los ocupados en el sector informal como trabajadores excedentes, supone que como éstos son, generalmente, los más pobres de todos los trabajadores, un cambio en la demanda traería la incorporación de los trabajadores no asalariados a la fuerza de trabajo asalariada. La investigación del PREALC utiliza frecuentemente al sector informal como una categoría analítica, operacionalizándola a ésta como trabajadores por su cuenta (excepto los profesionales), trabajadores familiares no remunerados y empleados domésticos. ${ }^{4}$

Por el contrario, Castells y Portes (1986) definen al sector informal como un "proceso" en el que el ingreso se genera a través de canales que evitan la regulación institucional, no obstante que el ambiente legal y social normalmente regula actividades similares. Al señalar que muchos participantes en la economía informal, tanto individuos como hogares, también son agentes sociales y económicos en el sector formal, estos autores enfatizan la interpenetración entre las unidades económicas, los individuos y las actividades, rechazando explícitamente el dualismo que implicaban los marcos teóricos de lo moderno-tradicional. En las sociedades capitalistas contemporáneas están articuladas y son mutuamente dependientes las formas de producción informal ostensiblemente atrasadas - como el trabajo industrial a domicilio o el comercio ambulante- y las formas de producción industrial más sofisticadas (Portes, 1985).

En América Latina las mujeres están concentradas en el sector informal en forma desproporcional (CEPAL, 1986; Berger y Buvinic, 1988). La encuesta de 1976 sobre las actividades informales en la ciudad de México, Guadalajara y Monterrey, encontró que $46 \%$ de las mujeres y $35 \%$ de los hombres desempeñaban actividades en el sector informal (Jusidman, 1989). La subcontratación y el trabajo eventual constituyen estrategias de ahorro de costos en

${ }^{3}$ La definición del PREALC que enfatiza las características de los trabajadores es inadecuada para captar otras variables que han ganado estatus en el campo teórico. Las cuestiones sobre los arreglos contractuales, los beneficios laborales, la legalidad y la seguridad en el empleo tradicionalmente no están incluidas en los censos o en las encuestas sobre empleo.

${ }^{4}$ Esta definición es problemática porque las empleadas domésticas tienen características muy diferentes a las de los trabajadores por cuenta propia y a las trabajadoras familiares no remuneradas. No obstante que las empleadas domésticas establecen una relación con hogares individuales más que con el proceso productivo son, sin embargo, trabajadoras asalariadas. Sus tareas son virtualmente indistinguibles de las de las trabajadoras no remuneradas en el hogar, en aquellos hogares en donde no existen empleadas domésticas. 
las industrias intensivas en mano de obra como la textil y la manufactura de ropa, caracterizadas por una gran proporción de trabajadores sin capacitación o semi-capacitados y que, en gran medida, se apoyan en el trabajo femenino. Las ocupaciones femeninas más comunes, como el comercio ambulante, empleadas de ventas en tiendas pequeñas de las colonias proletarias, preparación de alimentos y trabajo ilegal a domicilio en las industrias del calzado y la ropa, presentan proporciones altas de trabajadores por su cuenta o de trabajadores familiares no remunerados (Portes y Benton, 1984).

\section{Heterogeneidad estructural y el empleo femenino}

Las primeras investigaciones sobre el empleo femenino en América Latina intentan describir las características de las trabajadoras y diferenciarlas de las mujeres que, de acuerdo con las definiciones tradicionales, no trabajan (Elizaga, 1968; Hass, 1972; Youssef, 1974; Pantelides, 1976). En gran medida esta línea de investigación está vinculada al estudio de los diferenciales de la fecundidad. Debido a que se conceptualiza a las mujeres como trabajadores secundarios, virtualmente se ignoró la demanda de trabajo femenino y las características del mercado de trabajo urbano.

A mediados de los años setenta, los marcos conceptuales empezaron a incluir la función económica desempeñada por el trabajo doméstico sin retribución y las características familiares que afectan el nivel y tipo de trabajo femenino necesario para la reproducción de la fuerza de trabajo (De Barbieri, 1978; Benería, 1979; Meillassoux, 1981; Alonso, 1982; García, Muñoz y Oliveira, 1982; Benería y Roldán, 1987). Además de las restricciones usuales fundamentadas en la demanda de trabajo, la participación de las mujeres en modos de producción alternativos se derivó de la división del trabajo por género. Más que un refugio de último recurso, las actividades no asalariadas pueden ser una opción óptima, dado el conflicto entre las obligaciones laborales y las domésticas.

Al subrayar la interacción entre el sistema económico y el sistema patriarcal o de dominio masculino expresada especialmente a través de los roles del parentesco (Gailey, 1987), la investigación actual retoma el punto de vista de Castell y Portes acerca de que la relación formal-informal constituye una serie de interacciones complejas entre la economía y el Estado. Si la división del trabajo por géneros dentro del hogar limita las opciones de trabajo que las mujeres, si actuasen solas, podrían elegir, entonces, los programas para mejorar el nivel de calificación de las trabajadoras po- 
tenciales o incrementar su demanda carecen de significado. Las mujeres no son marginales en términos de sus calificaciones individuales, sino en términos de su disponibilidad para comprometerse con un empleo asalariado.

La importancia del empleo no asalariado para las mujeres significa, por lo tanto, más que la demanda limitada de trabajo. La segregación del empleo por sexo, que se apoya en el supuesto ideológico de que la principal obligación de las mujeres es ocuparse de su hogar, es uno de los principales vehículos del dominio masculino en las sociedades capitalistas (Hartmann, 1976). Una gama restringida de opciones ocupacionales reduce la movilidad ocupacional, especialmente en épocas de recesión, y hace posible el pago sistemático de salarios más bajos a las mujeres. La incapacidad de las mujeres trabajadoras de sostenerse por sí mismas las mantiene económicamente dependientes $\mathrm{y}$, de hecho, las obliga a casarse. Su doble carga de trabajo doméstico y no doméstico debilita aún más su posición en el mercado de trabajo. A su vez, los hombres se benefician de salarios más altos y de la división del trabajo doméstico. Esta reciprocidad entre la división jerárquica del trabajo dentro del hogar y en el mercado de trabajo es el resultado del constante reacomodo entre los sistemas del capitalismo y el patriarcado (Hartmann, 1976). Este reacomodo resulta más oneroso en épocas de dificultad económica, cuando las mujeres se ven obligadas a ejercer actividades no asalariadas mal pagadas como la única forma de contribuir al ingreso familiar.

Distribución ocupacional de las trabajadoras asalariadas y no asalariadas

En el cuadro 1 se explora la asociación entre la estructura ocupacional y la condición salarial. La mayoría de las trabajadoras no asalariadas están concentradas en el comercio (véase cuadro 1parte A). Los factores culturales y económicos asociados con el contacto personal, la proximidad física a los consumidores, el crédito y la menor inversión convierten a las actividades comerciales en una área de oportunidad para las trabajadoras no asalariadas. ${ }^{5}$

\footnotetext{
5 A pesar de los precios frecuentemente más altos, las pequeñas tiendas (denominadas misceláneas en Méxicol, por ejemplo, funcionan con eficacia en la ciudad de México debido a que grandes segmentos de la población carecen de un buen servicio de transporte que les permita trasladarse a los centros comerciales, y la gente que habita en los barrios empobrecidos desprovista de un espacio para almacenar debe comprar diariamente sus provisiones (García, 1988).
} 
Las ocupaciones especificas están asociadas con diferencias de edad, escolaridad y tamaño de la familia. Regularmente, las vendedoras ambulantes no asalariadas o las vendedoras de los mercados son mujeres extremadamente pobres con hijos pequeños, poca escolaridad formal y escasos recursos económicos (De Barbieri, 1984). Las trabajadoras no asalariadas con más recursos, tienen suficiente capital para establecer un negocio familiar. Las mujeres solteras, jóvenes con niveles medios de escolaridad son trabajadoras asalariadas de los grandes establecimientos comerciales.

Las diferencias de ingresos por condición salarial son triviales (véase cuadro 1-parte C). Casi 90\% del total de mujeres que ganan menos del salario mínimo legal son asalariadas. Este hallazgo indica en primer lugar, que los patrones evaden en gran medida el requisito del salario mínimo y en segundo lugar, que la mayoría de las trabajadoras ganan muy poco, independientemente de su condición salarial. El empleo no asalariado por tanto no es necesariamente un eufemismo de la pobreza. Más aún, en México, la política de deprimir artificialmente el salario mínimo conduce a escalas salariales tan bajas que muchos trabajadores asalariados deben complementar sus ingresos con trabajos múltiples, tiempo extra, actividades no asalariadas y subsidios públicos.

\section{Hipótesis}

El empleo asalariado versus el no asalariado constituyen mercados de trabajo competitivos para las mujeres en la medida en que la participación en uno u otro representa estrategias económicas alternativas. La decisión de trabajar y la elección entre empleo asalariado y no asalariado está condicionada por los atributos de la clase social, necesidad económica, disponibilidad de ayuda para el cuidado de los niños, y por los cambios en la demanda de trabajadores en categorías ocupacionales específicas.

La distribución de las mujeres por condición salarial está condicionada por las características que generalmente determinan el empleo femenino: edad, escolaridad, estado civil, tamaño de la familia, condición migratoria, género del jefe del hogar, participación en la fuerza de trabajo de otros miembros del hogar, estructura del hogar, y la presencia de niños, empleadas domésticas y personas mayores en los hogares. Algunas veces, las asociaciones se revierten debido principalmente a que el trabajo no asalariado se adapta más a las limitaciones impuestas por estas característi- 
CUADRO 1

Porcentaje de trabajadoras según la condición salarial, ocupación, sector económico y nivel de salario, ciudad de México, 1970

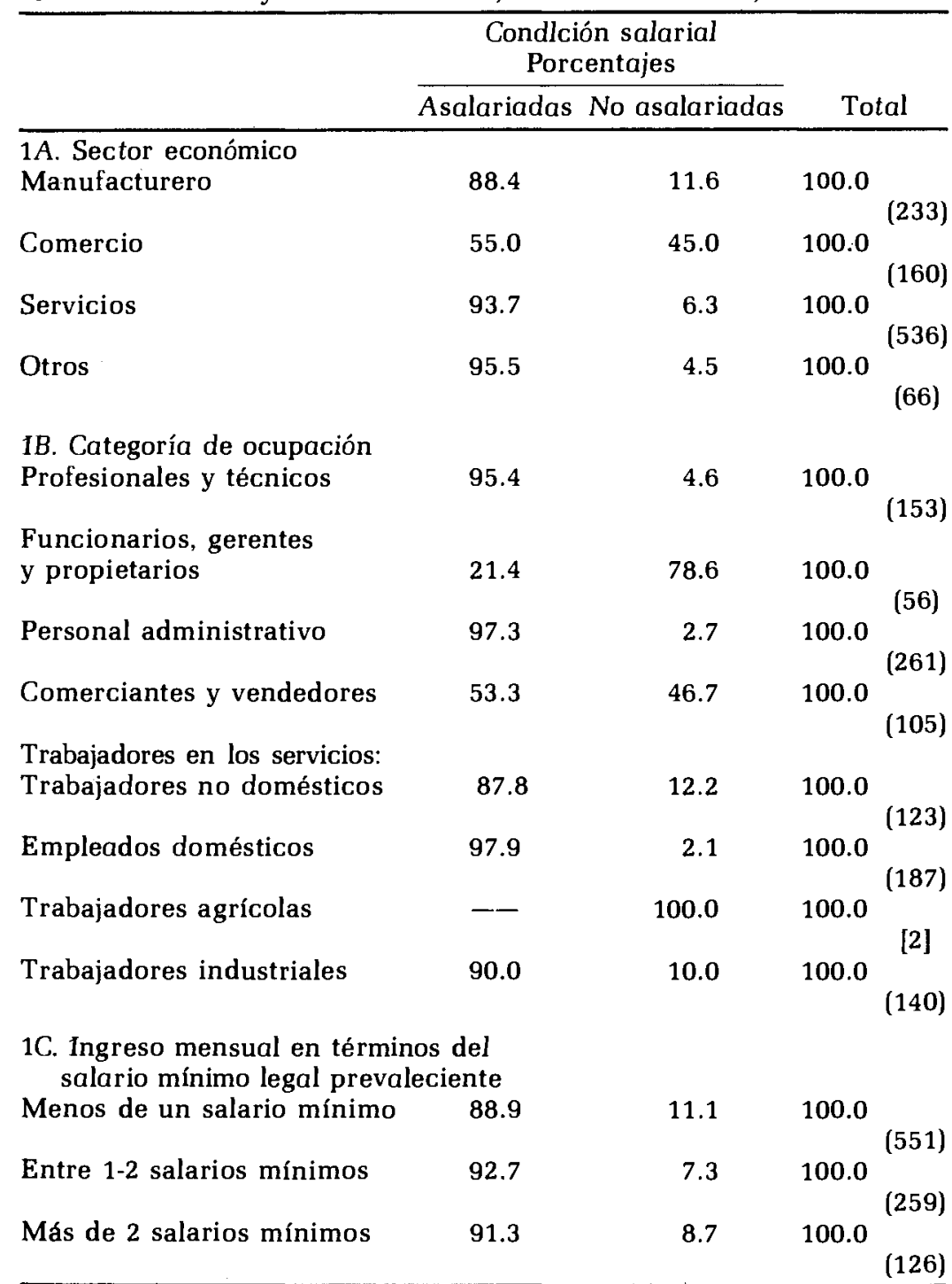

Notas: $1-A: \mathrm{N}=995$, Omisiones $=37 / 1032$ o $4 \%$ de los casos.

1-B: $N=1027$, Omisiones $=5 / 1032$ o menos de $1 \%$ de los casos.

1-C: $\mathrm{N}=936$, Omisiones $=96 / 1032$ o $9.3 \%$ de los casos.

Las cifras entre corchetes denotan que el tamaño de la celda es pequeño. 
cas. La dirección esperada en las relaciones de orden cero es la siguiente:

Relación hipotética

Determinantes socioeconómicos y demográficos de la oferta de trabajo femenino

\begin{tabular}{|c|c|c|}
\hline \multicolumn{3}{|c|}{ Ciudad de México, 1970} \\
\hline \multirow[b]{2}{*}{ Variable } & \multicolumn{2}{|c|}{ Condición salarial } \\
\hline & Asalariada & No asalariada \\
\hline \multicolumn{3}{|l|}{$\begin{array}{l}\text { Determinantes en el nivel } \\
\text { individual }\end{array}$} \\
\hline Edad & - & + \\
\hline \multicolumn{3}{|l|}{ Estado civil: } \\
\hline Soltera & + & - \\
\hline Casada actualmente & - & + \\
\hline Casada anteriormente & $+1-$ & + \\
\hline Condición migratoria & $+1-$ & + \\
\hline Fecundidad & - & + \\
\hline \multicolumn{3}{|l|}{$\begin{array}{l}\text { Determinantes en el nivel } \\
\text { del hogar }\end{array}$} \\
\hline Número de trabajadores del hogar & $+1-$ & + \\
\hline Jefe de hogar masculino & - & + \\
\hline Estructura de familia extendida & + & - \\
\hline \multicolumn{3}{|l|}{ Presencia de niños pequeños } \\
\hline en el hogar & - & + \\
\hline Empleadas domésticas en el hogar & + & - \\
\hline Personas mayores en el hogar & + & - \\
\hline
\end{tabular}

$$
\begin{aligned}
\text { Código: } \quad+\text { Relación positiva } \\
\quad-\text { Relación negativa } \\
+1-\text { La hipótesis de competencia sugiere que la relación puede } \\
\text { ser positiva o negativa }
\end{aligned}
$$

\section{Los determinantes de la condición salarial} en el nivel individual

\section{Escolaridad}

Las hipótesis alternativas de la competitividad determina la asociación entre la escolaridad y la condición salarial. La hipótesis de que el empleo asalariado aumenta con la escolaridad postula que las mujeres con menos escolaridad tienen pocas oportunidades de empleo y también supone que con la excepción obvia de las profesionales por cuenta propia, la mayoría de las actividades 
no asalariadas en la ciudad de México requieren poca capacitación o escolaridad. La evidencia de que la industrialización mexicana ha contribuido positivamente al crecimiento del empleo asalariado en el sector de los servicios al crear demanda sust antiva de servicios financieros y profesionales apoya este punto de vista (Muñoz y Oliveira, 1977; García, 1988). Han aumentado los trabajos asalariados para los trabajadores capacitados en ocupaciones tradicionalmente femeninas como resultado de la ampliación de los servicios de salud, escolaridad y bienestar, y por la necesidad de personal administrativo (Oliveira, 1989).

Un punto de vista alternativo es que la asociación entre empleo asalariado y la escolaridad tiene forma de U. El empleo asalariado es más alto entre las mujeres en los extremos de la escolaridad: mujeres sin escolaridad que trabajan como empleadas domésticas y mujeres que terminaron la primaria o más. Las mujeres que no completaron la escuela primaria son las que se encuentran en mayor desventaja porque el hecho de completar la escuela primaria es el umbral para muchos de los trabajos asalariados.

La relación entre escolaridad y empleo asalariado en la ciudad de México tiene forma de U (véase cuadro 2). Mientras que el empleo asalariado difiere relativamente poco en los niveles más bajos y más altos de la escolaridad, la proporción de mujeres asalariadas que no completaron la educación primaria es aproximadamente $15 \%$ menor que la de las mujeres que sí lo hicieron. Estos resultados constatan la existencia de mercados de trabajo no competitivos, diferenciados para las trabajadoras asalariadas: las mujeres sin escolaridad trabajan principalmente como empleadas domésticas mientras que las mujeres con más escolaridad están empleadas en puestos que requieren mayor capacitación.

CUADRO 2

Porcentaje de trabajadoras según la condición salarial y escolaridad, ciudad de México, 1970

\begin{tabular}{lccccc}
\hline & \multicolumn{4}{c}{$\begin{array}{c}\text { Condición salarial } \\
\text { Porcentaje }\end{array}$} & \\
\cline { 2 - 4 } Escolaridad & Asalariadas & No asalariadas & Total & $(\mathrm{N})$ \\
\hline Ninguna & 86.8 & 13.2 & 100.0 & $(121)$ \\
< Primaria completa & 77.4 & 22.6 & 100.0 & $(252)$ \\
Primaria completa o $>$ & 89.7 & 10.3 & 100.0 & $(649)$ \\
Omisiones = 10/1032 & & & & & \\
\hline
\end{tabular}


Edad y estado civil

El empleo asalariado disminuye con la edad y la transición de soltera a casada. Los patrones prefieren contratar mujeres jóvenes solteras que no estén agobiadas por las preocupaciones del hogar (Jelin, 1978). Debido al creciente gasto público en educación que se ha dado a lo largo del tiempo, las mujeres jóvenes solteras como grupo tienen también mayor escolaridad y se encuentran mejor capacitadas para desempeñar trabajos calificados. Las mujeres solteras con menor escolaridad son principalmente empleadas domésticas.

Las mujeres que trabajan se desempeñan en actividades que minimizan el conflicto entre los roles domésticos y los otros. ${ }^{6}$ Ocupaciones como el comercio ambulante, la preparación de alimentos, la costura de ropa o el trabajo industrial a domicilio pueden realizarse total o parcialmente en el hogar utilizando equipo y materiales comunes en él; los horarios de trabajo se adaptan más fácilmente a las demandas familiares y al cuidado de los niños; el número de horas trabajadas por día o semana es flexible, y puede utilizarse el trabajo familiar no remunerado en muchas tareas asociadas con el proceso de producción.

La edad y el estado civil diferencian claramente a las trabajadoras por condición salarial (véase cuadro 3). Independientemente del estado civil, las mujeres mayores tienen más probabilidad de ser no asalariadas e independientemente de la edad, las mujeres casadas actualmente tienen mayor probabilidad de ser no asalariadas. Entre las mujeres jóvenes, la diferencia en la proporción de solteras y las asalariadas casadas con anterioridad es pequeña, mientras que la proporción de trabajadoras no asalariadas casadas es casi ocho veces la de las solteras. Igualmente, la proporción de mujeres no asalariadas casadas mayores es tres veces más alta que la de las solteras mayores. La probabilidad de que las mujeres separadas, divorciadas y viudas sean no asalariadas es intermedia entre mujeres casadas y solteras.

\section{Fecundidad}

No obstante que la fecundidad alta desmotiva el trabajo, asalariado y facilita el empleo no asalariado, esta relación tiene como pivote

\footnotetext{
${ }^{6}$ Sin embargo, De Barbieri (1964b) advierte en contra de la extrapolación de la experiencia de las clases altas y medias a toda la sociedad. Es decir, la construcción ideológica subyacente del papel de las mujeres casadas se deriva no sólo del sistema patriarcal dominante sino también del sistema de relaciones de clase.
} 
CUADRO 3

Porcentaje de trabajadoras según la condición salarial, edad y estado civil, ciudad de México, 1970

\begin{tabular}{lrcr}
\hline & \multicolumn{3}{c}{ Estado civil } \\
\cline { 2 - 4 } Edad & Solteras & $\begin{array}{c}\text { Actualmente } \\
\text { casadas }\end{array}$ & Sep/Viu/Div \\
\hline Menores de 35 años & & & \\
$\quad$ Asalariadas & 97.5 & 77.9 & 94.7 \\
No asalariadas & 2.5 & 22.1 & 5.3 \\
Total & 100.0 & 100.0 & 100.0 \\
Núm. de casos & $(433)$ & $(190)$ & $(94)$ \\
35 y & & & 79.7 \\
Asalariadas & 87.3 & 62.5 & 20.3 \\
No asalariadas & 12.7 & 37.5 & 100.0 \\
Total & 100.0 & 100.0 & $(123)$ \\
Núm. de casos & $(55)$ & $(136)$ & \\
\hline
\end{tabular}

Casos omitidos: menos de $1 \%$ de los casos.

la disponibilidad de ayuda para el cuidado de los niños. El conflicto de roles impide que las mujeres con niños acepten empleo asalariado fuera del hogar. Al mismo tiempo, los patrones son renuentes a contratar mujeres cuyas obligaciones familiares las hacen estar menos comprometidas con su trabajo y susceptibles de ausentarse del mismo con frecuencia. La fecundidad alta no es un obstáculo para el empleo no asalariado porque éste es más compatible con las responsabilidades del cuidado de los hijos. Por lo tanto el empleo asalariado per se no debería verse afectado por el número de niños, sino más bien por la maternidad en sí misma. Por su parte, el tamaño de la familia está asociado con el trabajo no asalariado porque muchas actividades vinculadas con este tipo de ocupación son negocios familiares de pequeña escala que se

CUADRO 4

Porcentaje de trabajadoras según la condición salarial y tamaño de la familia, ciudad de México, 1970

\begin{tabular}{lcccc}
\hline & \multicolumn{3}{c}{$\begin{array}{c}c \\
\text { Pondición salarial }\end{array}$} & \\
Hijos nacidos vivos & Asalariadas & No asalariadas & Total & $(\mathrm{N})$ \\
\hline Ninguno & 95.1 & 4.9 & 100.0 & $(506)$ \\
1 & 90.1 & 9.9 & 100.0 & $(121)$ \\
$2-5$ & 78.1 & 21.9 & 100.0 & $(256)$ \\
$6+$ & 64.2 & 35.8 & 100.0 & $(134)$ \\
\hline
\end{tabular}

Omisiones $=15 / 1032$. 
apoyan en el trabajo familiar no remunerado, incluyendo el trabajo infantil (Selby, Murphy y Lorenzen, 1990).

La fuerte asociación positiva entre el tamaño de la familia y el empleo no asalariado indica claramente que, en realidad, las mujeres con familias grandes tienen mayor probabilidad de ser no asalariadas. Una disminución progresiva en el empleo asalariado por tamaño de la familia también señala hacia un efecto acumulado, es decir, mientras más niños tiene una mujer, menos tiene la posibilidad de cumplir con las demandas de su trabajo.

\section{Condición migratoria}

La asociación entre la condición migratoria y la salarial es teóricamente ambigüa. Por una parte, las mujeres migrantes están en desventaja competitiva en el mercado de trabajo asalariado urbano porque generalmente tienen menor escolaridad y son menos calificadas que las mujeres nacidas en la ciudad de México. ${ }^{7}$ Por lo tanto, tienen menor probabilidad que las mujeres originarias de la ciudad de México de ser no asalariadas. Las mujeres migrantes tienen también menos contactos o redes que puedan proporcionar información, ayudas recíprocas y económicas, y acceso a empleos asalariados. ${ }^{8}$ Estos factores, combinados con la motivación predominantemente económica que subyace la migración a la ciudad de México, obligan a los migrantes a recurrir a innumerables formas de actividad no asalariada para poder obtener un ingreso por demás limitado.

Alternativamente, la relación entre la condición migratoria y la condición salarial está condicionada por la escolaridad, la edad y el estado civil. Cuando se controla la escolaridad, no debería ha-

\footnotetext{
${ }^{7}$ Mientras que $7 \%$ de las nativas comparadas con $21 \%$ de migrantes nunca asistieron a la escuela, la proporción de nativas que completó la escuela primaria o más es casi el doble que la de las migrantes: 71 y $40 \%$, respectivamente.

${ }^{8}$ En vista del flujo migratorio de largo plazo a la ciudad de México, Garcia, Muñoz y Oliveira (1982), enfatizan la compleja mezcla nativo-migrante de la mayoría de los hogares en la ciudad de México. A pesar de que en esta investigación no examino este tema empíricamente, las mujeres migrantes casadas con un hombre originario de la ciudad pueden tener mejor acceso a redes sociales y económicas que las mujeres cuyos esposos son también migrantes. Cuando se controla la duración de la residencia en la ciudad de México y la composición migrante-nativo del hogar no se esperaría encontrar diferencias sustanciales entre nativos y residentes migrantes de largo plazo en la ciudad. Son esencialmente más importantes los temas ecológicos o comunitarios vis-d-vis la competencia entre las comunidades, la repetición de bienes y servicios ofrecidos y el acceso local a los materiales, que las cuestiones migrantes-nativos.
} 
ber diferencias significativas entre las proporciones de mujeres asalariadas originarias de la ciudad de México y las migrantes. Las variaciones en la distribución ocupacional están determinadas por la escolaridad. Tanto las migrantes con menor escolaridad que trabajan como empleadas domésticas como las originarias de la ciudad de México con mayor escolaridad probablemente son asalariadas.

Ochenta y ocho por ciento de nativas y $83 \%$ de migrantes son asalariadas (véase cuadro 5). Cuando se controla la escolaridad las diferencias son más sustanciales. A pesar de que menos originarias de la ciudad de México son no asalariadas, la proporción de ellas con poca o escasa escolaridad que son no asalariadas, es consistentemente más alta que la de las migrantes de origen rural, mientras que la proporción de mujeres originarias de la ciudad de México con mayor escolaridad que son no asalariadas es mucho más baja. ${ }^{9}$

Destacando la diversidad en los niveles de escolaridad de las migrantes, que frecuentemente no es señalada, los hallazgos sugieren primero, que las trabajadoras no asalariadas con mayor escolaridad probablemente son migrantes y segundo, que las redes facilitan a las originarias de la ciudad con menor escolaridad llevar a cabo actividades no asalariadas.

\section{Restricciones familiares}

Cuidado de los niños: la presencia de niños pequeños en el hogar

Anticipo una asociación negativa entre la presencia de niños muy pequeños en el hogar y el empleo asalariado debido a que la necesidad de atender a los niños se reduce cuando estos están en edad escolar.

Disponibilidad de ayuda para el cuidado de los niños: estructura del hogar, presencia de personas mayores y de empleadas domésticas

La disponibilidad de ayuda para el cuidado de los niños es un determinante clave del empleo asalariado. Los inconvenientes y costos del servicio profesional para el cuidado de los niños impide a

\footnotetext{
${ }^{9}$ El tamaño pequeño de cada celda hace que los datos sobre las migrantes de origen urbano no sea confiable.
} 
CUADRO 5

Porcentaje de trabajadoras según la condición salarial, condición migratoria y escolaridad, ciudad de México, 1970

\begin{tabular}{lrrrr}
\hline & & \multicolumn{3}{c}{ Escolaridad } \\
\cline { 3 - 5 } Condición migratoria & $\begin{array}{c}\text { Total } \\
\text { mujeres }\end{array}$ & $\begin{array}{c}\text { Sin } \\
\text { esco- } \\
\text { laridad }\end{array}$ & $\begin{array}{c}\text { Menos que } \\
\text { la primaria } \\
\text { compieta }\end{array}$ & $\begin{array}{c}\text { Primaria } \\
\text { compieta } \\
\text { o más }\end{array}$ \\
\hline Nativas: & & & & \\
$\quad$ Asalariadas & 88.3 & 78.6 & 70.5 & 92.4 \\
No asalariadas & 11.7 & 1.4 & 29.5 & 7.6 \\
$\quad$ Total & 100.0 & 100.0 & 100.0 & 100.0 \\
Núm. de casos & $(609)$ & $(28)$ & $(95)$ & $(484)$ \\
& & & & \\
Migrante de origen rural: & & & & \\
Asalariadas & 83.4 & 88.0 & 82.9 & 90.2 \\
No asalariadas & 16.5 & 12.0 & 17.1 & 19.8 \\
Total & 100.0 & 100.0 & 100.0 & 100.0 \\
Núm. de casos & $(318)$ & $(83)$ & $(140)$ & $(91)$ \\
& & & & \\
Migrante de origen urbano: & & & & \\
$\quad$ Asalariadas & 83.5 & 100.0 & 66.7 & 86.0 \\
$\quad$ No asalariadas & 16.5 & - & 33.3 & 14.0 \\
Total & 100.0 & 100.0 & 100.0 & 100.0 \\
Núm. de casos & $(82)$ & {$[7]$} & {$[15]$} & $(57)$ \\
\hline
\end{tabular}

Casos omitidos $=23 / 1032=2.2 \%$ de casos.

Las cifras entre corchetes denotan celdas pequeñas.

las mujeres que no cuentan con recursos adecuados a aceptar un trabajo asalariado. El empleo asalariado es posible sólo si el cuidado de los niños puede ser proporcionado por otros miembros del hogar: es decir, en los hogares extendidos, especialmente aquellos con personas mayores, o en los hogares que cuentan con empleadas domésticas. Por lo tanto, las mujeres pertenecientes a hogares en los que no existe ayuda para el cuidado de los niños tienen mayor probabilidad de ser no asalariadas.

La proporción de mujeres no asalariadas es aproximadamente $30 \%$ mayor en los hogares con niños pequeños (véase cuadro 6 ). La presencia de empleadas domésticas proporciona también un impulso significativo al empleo asalariado; la proporción de mujeres asalariadas es tres veces mayor en los hogares con presencia de empleadas domésticas que en los hogares en los que las mujeres deben asumir por sí mismas todas las obligaciones domésticas. La estructura del hogar y la presencia de personas mayores en él no son estimadores robustos de la condición salarial. 
CUADRO 6

Porcentaje de trabajadoras según la condición salarial y características seleccionadas de necesidad de cuidado de niños y disponibilidad, ciudad de México, $1970(\mathrm{~N}=1032)$

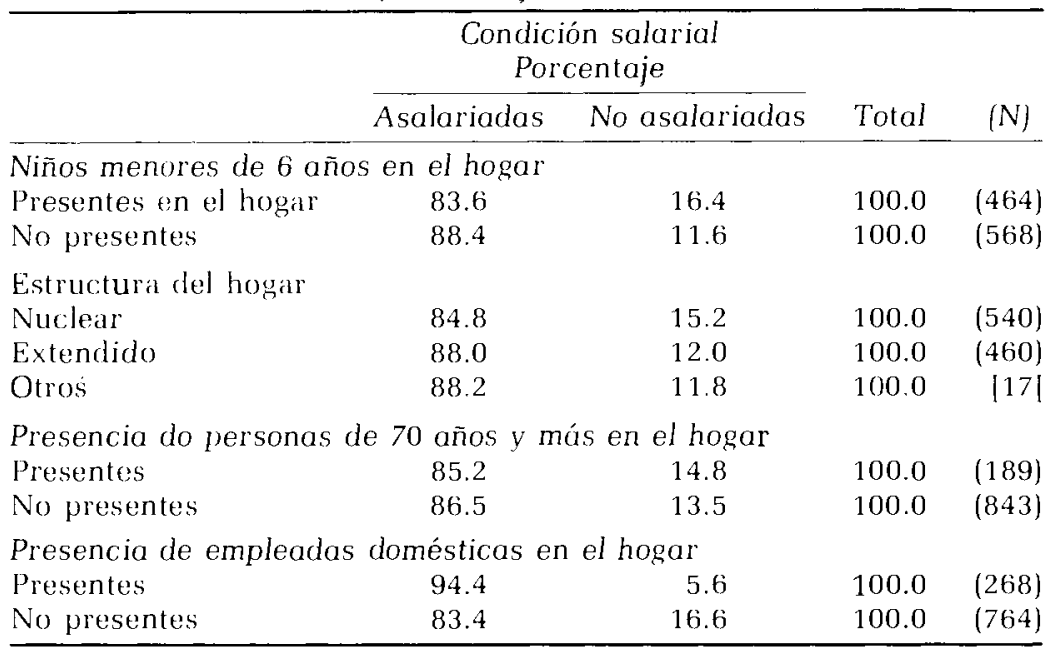

Casos omitidos: estructura del hogar - omitidos $=9 / 1032$.

Género del jefe del hogar

La asociación entre los hogares encabezados por mujeres y empleo no asalariado de la mujer depende del estado civil. Las mujeres que viven en hogares con jefe femenino tienen mayor probabilidad de ser no asalariadas porque la jefatura femenina generalmente implica la disolución permanente o temporal de la unión de la jefa del hogar. Sin embargo, cuando se controla el estado civil, no existe una razón teórica para que el género del jefe del hogar influya sobre la condición salarial. El trabajo no asalariado, no obstante el bajo ingreso que genera, ofrece la ubicación flexible del lugar de trabajo y horarios que minimizan el conflicto de roles. De hecho, la ocupación es uno de los principales factores que explican las diferencias de ingresos entre hombres y mujeres jefes de hogar en América Latina (CEPAL, 1986; Berger y Buvinic, 1988). A pesar de esto, la necesidad económica predomina sobre los obstáculos domésticos al empleo, aún para las mujeres casadas. Los miembros empobrecidos de los hogares encabezados por mujeres deben trabajar en cualquier trabajo disponible y hacer cualesquiera de los arreglos necesarios para poder hacerlo, sin importar que tan onerosos resulten. 
El cuadro 7 confirma que las mujeres actual o anteriormente casadas que viven en hogares encabezados por mujeres tienen mayor probabilidad de ser asalariadas que sus contrapartes que viven en hogares con jefe masculino. No obstante, la pobreza relativa de los hogares con jefe femenino generalmente estimula el empleo asalariado, las mujeres actualmente casadas tienen mayor probabilidad de ser asalariadas que las mujeres anteriormente casadas. La condición salarial de las mujeres solteras no se ve afectada por el género del jefe del hogar.

\section{CUADRO 7}

Porcentaje de trabajadoras asalariadas según el género del jefe del hogar y estado civil, ciudad de México, $1970(N=1031)$

\begin{tabular}{|c|c|c|c|c|c|c|}
\hline \multirow{2}{*}{$\begin{array}{l}\text { Género del } \\
\text { jefe del hogar }\end{array}$} & \multicolumn{6}{|c|}{$\begin{array}{l}\text { Porcentaje asclariado } \\
\text { Actualmente }\end{array}$} \\
\hline & \multicolumn{2}{|c|}{ Soltero } & \multicolumn{2}{|c|}{ Casado } & \multicolumn{2}{|c|}{ Sep/Viu/Div } \\
\hline Total de mujeres & 96.3 & $(470)$ & 71.5 & (233) & 86.2 & (187) \\
\hline $\begin{array}{l}\text { Hogar con jefe } \\
\text { mujer }\end{array}$ & 97.2 & $(138)$ & 92.3 & (24) & 80.9 & $(93)$ \\
\hline $\begin{array}{l}\text { Hogar con jefe } \\
\text { hombre }\end{array}$ & 96.0 & $(332)$ & 69.7 & $(209)$ & 92.2 & (94) \\
\hline
\end{tabular}

Casos omitidos: $1 / 1032=$ menos de $1 \%$ de los casos.

Trabajadores adicionales en el hogar

Existen argumentos alternativos que declaran la asociación entre el número de trabajadores adicionales por hogar y la condición salarial. Por un lado, el empleo no asalariado está asociado positivamente con los trabajadores familiares no remunerados en las empresas familiares. Alternativamente, los hogares con trabajadores numerosos o son hogares extendidos en los que hay disponibilidad de sustitutos para el cuidado de los niños o son hogares en etapas avanzadas del ciclo de vida con hijos en edad de trabajar. En cualquier caso, cuando las responsabilidades del cuidado de los hijos se reducen, las mujeres están en mejor posición para aceptar empleos asalariados fuera del hogar.

La asociación entre el número de trabajadores adicionales por hogar y el empleo no asalariado no obstante ser positiva, es débil, sugiriendo que la participación de otros miembros del hogar en la fuerza de trabajo no es un determinante significativo del empleo asalariado. 


\section{CUADRO 8}

Porcentaje de trabajadoras según la condición salarial y número de trabajadores adicionales en el hogar, ciudad de México, $1970(N=1032)$

\begin{tabular}{lccrc}
\hline \multirow{2}{*}{$\begin{array}{l}\text { Trabajadores adicionales } \\
\text { en ei hogar }\end{array}$} & $\begin{array}{c}\text { Condición saiariai } \\
\text { Porcentaje }\end{array}$ & & \\
\cline { 2 - 3 } & Asaiariadas & No asalariadas & Total & $(\mathrm{N})$ \\
\hline Sin trabajadores adicionales & 88.5 & 11.5 & $\mathbf{1 0 0 . 0}$ & $(78)$ \\
1 trabajador adicional & 86.3 & 13.7 & $\mathbf{1 0 0 . 0}$ & $(183)$ \\
2 + trabajadores adicionales & 86.0 & 14.0 & $\mathbf{1 0 0 . 0}$ & $(771)$ \\
\hline
\end{tabular}

Casos omitidos $=0$.

Análisis multivariado de los determinantes de los asalariados versus no asalariados

Para resumir los planteamientos realizados hasta aquí, además del vínculo entre los atributos individuales tales como la edad, escolaridad y condición migratoria y la demanda de tipos específicos de trabajo en el mercado urbano, la condición salarial entre las mujeres trabajadoras de la ciudad de México en 1970 está también determinada por la división del trabajo en el hogar y el conflicto entre las obligaciones domésticas y el cuidado de los niños. El estado civil, el tamaño de la familia, la participación de otros miembros del hogar en la fuerza de trabajo, la necesidad de cuidar a los niños y la disponibilidad de fuentes alternativas para el cuidado de los hijos son los factores estimados para determinar la condición salarial.

Utilizando la regresión logística, especifiqué modelos alternativos en los que la variable dependiente (WAGESTAT) es el logaritmo natural de los momios del empleo asalariado. Los modelos se ajustan utilizando PROC I.OCiST del paquete estadístico SAS. El modelo 1 considera la relación entre wogestat y los determinantes hipotéticos del empleo asalariado a nivel individual: edad, escolaridad, estado civil, condición migratoria y tamaño de la familia. El modelo 2 incluye variables a nivel del hogar, además de las variables individuales: estructura del hogar, número de trabajadores adicionales en él, género del jefe del hogar, y la presencia de niños pequeños, personas mayores y empleadas domésticas. El modelo 3 contiene todos los términos anteriores y las siguientes interacciones teóricas: estado civil y género del jefe del hogar; presencia de niños pequeños y empleadas domésticas; presencia de niños pequeños y personas mayores, y presencia de niños pequeños y estructura del hogar. 
Razones logarítmicas de máxima verosimilitud de los modelos

El cuadro 9 evalúa la bondad de ajuste de los modelos.

CUADRO 9

Razones logarítmicas de máxima verosimilitud en los modelos alternativos para predecir el empleo asalariado de trabajadoras a partir de variables individuales y familiares

\begin{tabular}{|c|c|c|c|}
\hline & Modelo & Modelo $G^{2}$ & Modelo DF \\
\hline (Indiv) & Modelo 1 & 150.40 & 11 \\
\hline (IndivHH) & Modelo 2 & 166.53 & 18 \\
\hline (Teórico) & Modelo 3 & 178.24 & 24 \\
\hline Delta $G_{2}$ Modelo $2-$ & Modelo 1 & 16.13 & 7 \\
\hline Delta $G_{2}$ Modelo 3 - & Modelo 2 & 11.71 & 6 \\
\hline
\end{tabular}

Representando la gama de los determinantes en el nivel individual del empleo asalariado como "I" y la gama de las variables familiares como "H", expreso este modelo como

$$
L_{n}[(P / 1-P)]=a+\Sigma b_{i}\left(I_{i}\right)+\Sigma b_{h}\left(H_{h}\right)
$$

en donde $(P / 1-p)$ es el momio, o la máxima verosimilitud de obtener un "si" por respuesta (si $1=$ "si" y $0=$ "no") de empleo asalariado, es la razón $\left[P_{i} /\left(1-P_{i}\right)\right]$, en donde $P$ es la proporción de mujeres trabajadoras asalariadas. $\mathrm{Al}$ agregar los principales efectos de las variables familiares se obtiene un incremento estadísticamente significativo del $\mathrm{G}^{2}$ a un nivel de $\mathrm{p}=.05$. La incorporación de los términos de interacción en el modelo 3 no es significativa. Por lo tanto, de los modelos presentados, el modelo 2 es el mejor instrumento para predecir el empleo asalariado. ${ }^{10}$

\footnotetext{
${ }^{10}$ Comparé los resultados descritos en el cuadro 9 con una prueba alternativa de bondad de ajuste, los Coeficientes de Información Bayesiana, o BIC's (Raf. ferty, 1986). Aquí la comparación se realiza con un modelo básico de determinación del empleo asalariado basado en las variables individuales.

$\mathrm{mc}^{*}$ se define como (Modelo $\mathrm{X}^{2}-$ d.f.* $\ln (\mathrm{N})$ ), en donde $\mathrm{N}$ es el número de casos en el análisis. Mientras más grande sea BIC*, mayor probabilidad tiene el modelo.

El interrogante es si cuando se incorporan las variables familiares y las interacciones el modelo de determinación del empleo asalariado es significativamente mejor que el modelo basado únicamente en las variables individuales. Los resultados que se presentan en el cuadro 9 me llevan a esperar que las Bic:* más grandes deberían corresponder al modelo que contiene tanto las variables individuales como las familiares de mayor significancia (modelo 2).
} 


\section{Bondad de ajuste de los modelos}

El cuadro 10 considera la asociación entre la probabilidad del empleo asalariado estimado por deciles en cada modelo y la proporción observada de trabajadoras asalariadas (Hosmer y Lemshow, 1989).

CUADRO 10

Probabilidades observadas y pronosticadas del empleo asalariado según modelos alternativos de determinación de la condición asalarial $(N=1019)$

\begin{tabular}{|c|c|c|c|c|c|c|}
\hline \multirow{3}{*}{$\begin{array}{c}\text { Probabilidad } \\
\text { pronosticada } \\
\text { para cada mujer }\end{array}$} & \multicolumn{6}{|c|}{$\begin{array}{c}\text { Proporción observada de los trabajadoras } \\
\text { asalariadas }\end{array}$} \\
\hline & \multicolumn{2}{|c|}{ Modelo 1} & \multicolumn{2}{|c|}{ Modelo 2} & \multicolumn{2}{|c|}{ Modelo 3} \\
\hline & $N$ & $0 \%$ & $N$ & $0 / 0$ & $N$ & $0 \%$ \\
\hline (1) & (2) & (3) & (4) & (5) & (6) & (7) \\
\hline $0-10$ & - & -- & - & - & -- & - \\
\hline $11-20$ & $\cdots$ & - & - & - & -- & - . \\
\hline $21-30$ & -- & -- & - & $\ldots$ & 2 & 00.0 \\
\hline $31-40$ & -- & - & 3 & 33.3 & 14 & 42.9 \\
\hline $41-50$ & 28 & 64.3 & 38 & 55.3 & 21 & 52.4 \\
\hline $51-60$ & 39 & 56.4 & 54 & 59.2 & 57 & 56.1 \\
\hline $61-70$ & 89 & 60.7 & 59 & 67.8 & 67 & 64.2 \\
\hline $71-80$ & 133 & 76.7 & 119 & 70.6 & 86 & 73.2 \\
\hline $81-90$ & 156 & 81.4 & 155 & 81.9 & 155 & 83.9 \\
\hline $91-100$ & 591 & 95.9 & 604 & 96.9 & 607 & 96.4 \\
\hline
\end{tabular}

Cásos omitidos $=13 / 1023$.

Cuadro A: Resumen de estimadores para varios modelos para la determinación del empleo asalariado, ciudad de México, 1970

\begin{tabular}{clcccc}
\hline Modelo & Variables & $N$ & Modelo $G^{2}$ & Modelo DF & BIC $^{\star}$ \\
\hline 1 & (I) & 1036 & 150.40 & 11 & 74.03 \\
2 & (I, H) & 1032 & 166.53 & 18 & 41.49 \\
3 & (I, H, 1-A) & 1009 & 178.24 & 24 & 12.24 \\
\hline
\end{tabular}

Contrario a mis expectativas, la incorporación de otros factores al modelo básico no mejoró significativamente el modelo para la determinación del empleo asalariado de las mujeres trabajadoras en la ciudad de México. Estos resultados señalan el hecho de que los resultados pueden diferir dependiendo del método estadístico y los criterios utilizados. De preferencia los BIC*s se utilizan para la comparación de diferencias en las chi cuadradas y los grados de libertad de modelos no jerárquicos. Como en este análisis los modelos son jerárquicos, fundamento el resto del análisis sobre los hallazgos descritos en el cuadro 9. 
Cada modelo proporciona una probabilidad de empleo asalariado para cada mujer trabajadora. Estas probabilidades están agrupadas en categorías estimadas por deciles (columna 1). Las frecuencias se refieren al número de trabajadoras cuya probabilidad estimada de empleo asalariado se ubica en la categoría estimada correspondiente por deciles (columnas 2, 4 y 6). Los porcentajes (columnas 3,5 y 7) indican la proporción de esas trabajadoras que en realidad son asalariadas.

Comparo los modelos evaluando la asociación entre la proporción estimada y la observada de mujeres asalariadas en la fuerza de trabajo para cada decil. El cuadro 10 indica que ninguno de los modelos estima muy bien el empleo asalariado. Debido a que casi $90 \%$ de todas las trabajadoras son asalariadas, la distribución es altamente asimétrica, sin casos en las categorías estimadas más bajas. No obstante, en los modelos 2 y 3 , los casos están de alguna forma mejor distribuidos, los modelos no son notoriamente más precisos en sus estimaciones que el modelo 1.

Estos hallazgos señalan diversos puntos metodológicos y teóricos. Primero, a pesar de que las hipótesis parecen ser intuitivamente razonables, los datos pueden ser inadecuados para captar los fenómenos sociales subyacentes. Esto es especialmente probable en el caso de las variables próximas para el cuidado de los niños y la agregación de ingresos. Segundo, al contrario de lo esperado, un número de factores incluidos en los modelos no son determinantes significativos del empleo asalariado. Esto permite conocer que la alta proporción de trabajadores asalariados en la ciudad de México está, primordialmente, en función de la estructura económica más que en función de las características de los trabajadores por sí mismos. De esta suerte, los hallazgos apuntan hacia la conclusión de que el empleo no asalariado es un aspecto estructural del desarrollo capitalista de México y es menos vulnerable a los cambios en el nivel de capacitación de la fuerza de trabajo, tal como los teóricos de la modernización o los de la marginalidad afirmarían.

Desde los años cincuenta, la industrialización de la ciudad de México y el crecimiento concomitante de los servicios amplió significativamente las oportunidades de empleo asalariado en la capital. La difundida definición por género de las ocupaciones originó también una estructura ocupacional altamente estratificada por lo que, para 1970 las mujeres que trabajaban en la industria se empleaban, principalmente, en la producción de bienes noduraderos (tabaco, textiles, alimentos y bebidas, zapatos y vestidos). Las trabajadoras asalariadas en los servicios se concentraban en el área de la salud, la educación y bienestar, como 
oficinistas y, por supuesto, en el servicio doméstico. Por el contrario, una gran proporción de trabajadoras no asalariadas laboraban en el comercio. Considerando la disminución progresiva de la proporción de trabajadoras que se desempeñaban en esta rama de actividad entre 1930 y 1970 (Oliveira y Muñoz, s.f.), resulta atractivo sugerir que la proliferación de supermercados, grandes almacenes, cadenas de restaurantes y otras empresas comerciales de gran escala redujo este campo tradicional de actividad no asalariada de las mujeres en la ciudad de México, en 1970.

\section{Comparación de los efectos de las variables explicativas}

El análisis de los coeficientes de determinación del empleo asalariado está basado en el modelo 2 .

El cuadro 11 confirma la mayoría de las relaciones descritas anteriormente. No obstante que todos los signos presentan la dirección esperada, sólo los coeficientes correspondientes a estado civil, edad, escolaridad, presencia de empleadas domésticas y de personas mayores en el hogar son estadísticamente significativas. La mayoría de las variables no.significativas tienen errores estándar grandes, haciendo imposible determinar la verdadera magnitud de sus efectos. Una vez más estos resultados sugieren que las características individuales y familiares afectan en menor medida la determinación del empleo asalariado que lo que previamente se creía.

\section{Estado civil}

El mejor predictor del empleo asalariado es el estado civil. Las mujeres actualmente casadas tienen menos probabilidad de ser asalariadas que las mujeres en cualquier otra categoría de estado civil. La probabilidad estimada por el modelo de que las mujeres actualmente casadas sean asalariadas es 0.81 , comparada con una probabilidad de 0.91 para todas las otras mujeres.

\section{Edad}

Las mujeres jóvenes tienen significativamente mayor probabilidad de ser asalariadas que las mujeres mayores. La probabilidad estimada por el modelo de que las mujeres menores de 35 años sean asalariadas es 0.93 , comparada con 0.86 para las mujeres de 35 y más años. 
CUADRO 11

Coeficientes y contribución al logito total para el modelo $2(\mathrm{~N}=1019)$

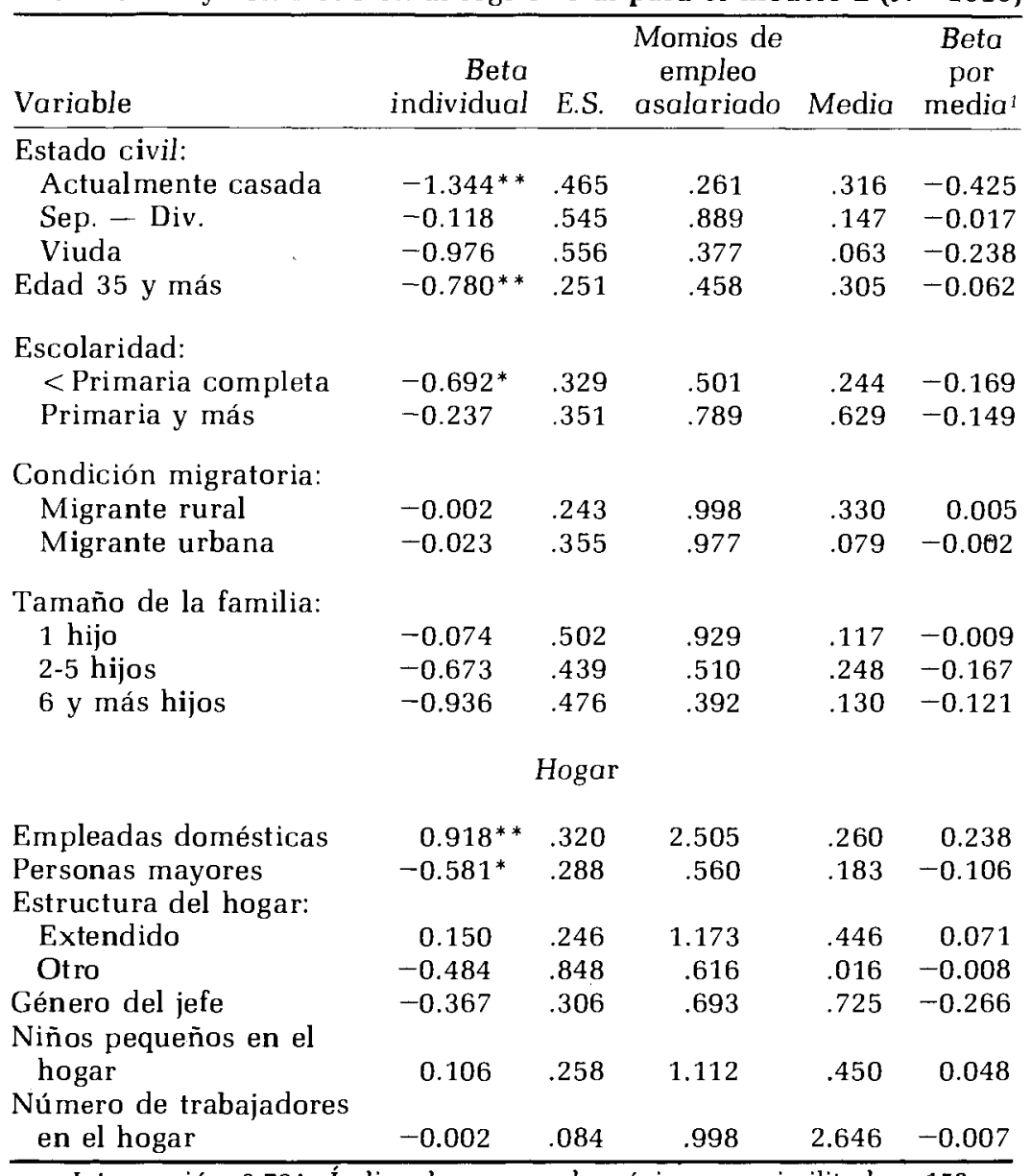

Intersección: 3.764 Índice de razones de máxima verosimilitud $=.158$ $\mathrm{G} 2=165.53(\mathrm{df}=18) \quad$ Medida del logito $=2.376$

${ }^{1}$ Contribución al logito.

* Significativo a nivel 0.05 .

** Significativo a nivel 0.01 . 


\section{Escolaridad}

La asociación entre escolaridad y empleo asalariado tiene forma de U. El coeficiente para las mujeres que no completaron la primaria es negativa y significativa a un nivel de $p=0.05$. El coeficiente para las mujeres que completaron la primaria no es significativa. Esto significa que hay poca diferencia entre las proporciones de mujeres asalariadas en la categoría omitida (mujeres sin escolaridad), y la categoría no significativa (trabajadoras asalariadas que completaron la escuela primaria). La probabilidad de que las mujeres que no completaron la primaria tengan empleo asalariado es 0.86 , comparada con la probabilidad de 0.93 para todas las otras mujeres.

\section{Empleados domésticas en el hogar}

Las trabajadoras femeninas que emplean servicio doméstico tienen más probabilidad de ser asalariadas. La probabilidad de empleo asalariado para las mujeres que contratan empleadas domésticas es 0.96 comparada con una probabilidad de 0.89 de las mujeres que no cuentan con este tipo de servicio.

\section{La presencia de personas mayores en el hogar}

El coeficiente negativo significativo para la presencia de personas mayores en el hogar desacredita el argumento de que éstas representan una fuente de ayuda para el cuidado de los niños. La probabilidad estimada por el modelo de que de las mujeres que viven en hogares con una o más personas mayores sean asalariadas es 0.87 , comparada con la probabilidad de 0.92 para las mujeres que provienen de hogares en los que no hay personas mayores. Hay dos posibles interpretaciones para estos resultados: que las personas mayores son una carga que impide que las mujeres trabajen fuera de la casa o que funcionen como trabajadoras sin remuneración en empresas familiares. Como esta investigación sólo considera la participación en la fuerza de trabajo de mujeres entre los 20 y 49 años, no hay manera de probar estas suposiciones.

\section{Diferencias al interior de las categorías de trabajadoras}

Por último, para apreciar mejor la heterogeneidad ocupacional al interior y entre las clases de trabajadoras, me aboco al análi- 
sis de las diferencias dentro de las categorías de trabajadoras asalariadas y no asalariadas. Distingo a las mujeres no asalariadas de acuerdo con la ubicación de su lugar de trabajo y con el número de empleados que supervisan, esperando encontrar que la mayoría de las trabajadoras no asalariadas no tienen responsabilidades de supervisión, o en el mejor de los casos, muy pocas." También distingo a las empleadas domésticas de otras trabajadoras asalariadas y comparo a cada grupo con las no asalariadas. ${ }^{12}$

El cuadro 12 muestra la distribución de las trabajadoras de acuerdo con una tipología de categorías del empleo. Esta distribución refleja la estructura del empleo del mercado de trabajo urbano y las diferencias sociales y económicas subyacentes entre las trabajadoras mismas. En 1970, las trabajadoras estaban concentradas en la parte inferior de la estructura ocupacional: aproximadamente $40 \%$ de las trabajadoras asalariadas son trabajadoras manuales sin capacitación y otro $40 \%$ son trabajadoras no-manuales sin responsabilidades de supervisión. Cerca de $75 \%$ del total de trabajadoras no asalariadas son trabajadoras por su cuenta sin empleados o trabajadoras familiares sin remuneración; un 10\% adicional son patrones que sólo utilizan trabajo no-remunerado, principalmente niños y otros miembros de la familia. Más de un tercio del total de trabajadoras no asalariadas no tienen un lugar de trabajo distinto al hogar. Presumiblemente, estas mujeres trabajan en su casa o como vendedoras ambulantes. ${ }^{13}$

\footnotetext{
${ }^{11}$ Como supongo que la mayoría de las mujeres no tengan responsabilidades de supervisión, distingo a las mujeres que trabajan por su cuenta que no tienen trabajadores a su cargo de aquéllas que tienen uno o más trabajadores.

${ }^{12}$ No obstante, la falta de información y lo pequeño de las muestras de los subgrupos impiden la posibilidad de profundizar el análisis multivariado, este enfoque descriptivo basado en categorías preexistentes me permite trabajar con la información disponible y hacer aportes al conocimiento actual, especialmente, debido a que el análisis empírico detallado de la heterogeneidad ocupacional de las mujeres trabajadoras en la ciudad de México es relativamente limitado.

${ }^{13}$ En países como México la importancia de las pequeñas unidades empresariales se deriva de la forma en que reclutan al trabajador, la forma en que se ofrece el trabajo, la relación entre propietarios y trabajadores y las relaciones entre los propietarios mismos (Giner de los Ríos, 1984). Generalmente, las empresas muy pequeñas son aquellas sin "suficientes recursos para tomar decisiones de producción independientes de las decisiones de consumo" (Giner de los Ríos, 1984: 1-2). Debido a que la mayoría de las mujeres no asalariadas están empleadas en tal tipo de empresas, es bastante clara la interdependencia entre las características del hogar y las del trabajo.
} 
CUADRO 12

Tipología del empleo asalariado y no asalariado, ciudad de México, $1970(\mathbf{N}=985)$

Tipo de Porcentaje del total de trabajador trabajadores

1.

Asalariados

a. No manuales

1a. con responsabilidad de supervisión

2a. $\sin$ responsabilidad de supervisión

b. Manuales

1b. Capacitados

2b. Sin capacitación

43.0

Total

100.0

2. No asalariados:

a. Empleadores

2a. Más de 5 trabajadores con pago

2b. 1-4 trabajadores con pago

2c. Empleadores con trabajadores sin pago

b. Trabajadores independientes - sin trabajadores

1b. No manuales

2b. Manuales

c. Trabajadores familiares no remunerados

23.8

Total

99.9

\footnotetext{
${ }^{a}$ Los números entre paréntesis son frecuencias.

Casos omitidos: asalariados $=4 / 890=$ menos de $1 \%$ de los casos. no asalariados $=12 / 142=8.4 \%$ de los casos.
} 


\section{Las vendedoras ambulantes}

Las investigaciones realizadas al principio de los años setenta acerca de las mujeres migrantes mazahuas y otomíes que trabajan como vendedoras ambulantes en la ciudad de México documentan que, la mayoría son jóvenes, analfabetas, no hablan español y viven en la más profunda pobreza. Pocas de estas mujeres tenían esposos o padres que poseían trabajos permanentes, y el ingreso derivado de las ventas del ambulantaje con frecuencia constituía la única fuente de ingresos para la sobrevivencia de la familia (Arizpe, 1979). No obstante que la venta en la calle no es una ocupación limitada a las "marías" mazahuas y otomíes descritas por Arizpe, su dolorosa experiencia proporciona un contexto para entender mejor la vida de las vendedoras ambulantes en la capital.

Cerca de $15 \%$ de las mujeres ocupadas en el comercio son vendedoras ambulantes, de ellas $77 \%$ son asalariadas. Por lo tanto, a diferencia de lo que establece el conocimiento convencional de que el ambulantaje en la ciudad de México es una forma de negocio familiar en el que las mujeres y sus hijos venden productos hechos en casa, la evidencia señala que las ventas ambulantes forman parte de una cadena de vínculos de subcontratación en el que los individuos son contratados por los productores o intermediarios para vender productos manufacturados. La viabilidad de áreas como Tepito, famoso por la venta en la calle de ropa, zapatos, artículos para el hogar, juguetes y "fayuca", o contrabando, está basada en las redes de comerciantes e intermediarios que obtienen su mercancía de los mayoristas que importan ilegalmente artículos eléctricos y electrónicos o de los productores quienes, para evitar impuestos y transferencias, trasladan la producción a talleres clandestinos o a trabajadores individuales y contratan vendedores ambulantes para vender sus productos a comisión (Uchitelle, 1990). Para muchas mujeres pobres, la venta en la calle es una actividad que hace innecesario el cuidado de los niños porque éstos acompañan a sus madres y, desde muy corta edad, las ayudan en sus labores. ${ }^{14}$

${ }^{14}$ Otra categoría ocupacional de interés es la venta en los mercados. Desafortunadamente. la información no presenta una categoria ocupacional por separado para las vendedoras en los mercados. En América Latina la venta en el mercado es una importante rama del comercio que permite también que las mujeres reconcilien el cuidado de los niños con el trabajo (Bunster y Chaney, 1989). 
CUADRO 13

Porcentaje de distribución de trabajadoras según clase de trabajadora e ingresos

\begin{tabular}{lccc}
\hline & \multicolumn{3}{c}{ Clase trabajadora } \\
\cline { 2 - 4 } $\begin{array}{l}\text { Categoría } \\
\text { de ingresos }\end{array}$ & $\begin{array}{c}\text { Empleadas } \\
\text { domésticas }\end{array}$ & $\begin{array}{c}\text { Demás } \\
\text { asalariadas }\end{array}$ & No-asalariadas \\
\hline <1 S.M. ${ }^{*}$ & $98.6 \%$ & $43.5 \%$ & $67.0 \%$ \\
1-2 S.M. & .0 .9 & 38.2 & 20.9 \\
$>2$ S.M. & 0.5 & 18.3 & 12.1 \\
Total & 100.0 & 100.0 & 100.0 \\
Núm. de casos & $(222)$ & $(623)$ & $(91)$ \\
\hline
\end{tabular}

Casos omitidos $=96 / 1032$ o $9.3 \%$

* S.M.: Salario mínimo.

Las empleadas domésticas en la ciudad de México

El desglose de las asalariadas en empleadas domésticas y otras trabajadoras aclara las diferencias al interior de la categoría de las trabajadoras.

Dentro de cada categoría salarial, la proporción de mujeres no asalariadas en los niveles de ingreso más bajo y más alto se ubica entre las empleadas domésticas y otras mujeres asalariadas. Mientras que casi ninguna empleada doméstica gana más del doble del salario mínimo legal, ${ }^{15}$ aproximadamente $12 \%$ de las no asalariadas y $18 \%$ de las trabajadoras asalariadas se encuentran en esa categoría de ingreso. De esta forma, el empleo no asalariado surge como un terreno intermedio en el que, a cambio de una mayor compatibilidad entre las responsabilidades domésticas y las laborales, las mujeres mayores, casadas y con menor escolaridad encuentran un vehículo para contribuir al ingreso monetario del hogar. El cuadro 14 considera el desglose entre las empleadas domésticas y las demás trabajadoras asalariadas en términos de edad, escolaridad, estado civil, tamañó de la familia y condición migratoria.

La mayor parte de las trabajadoras no asalariadas muestra un patrón intermedio entre las empleadas domésticas y otras trabajadoras asalariadas. La mayoría de las empleadas domésticas son migrantes rurales con escasa o ninguna escolaridad. La escolari-

${ }^{15}$ A pesar de que las empresas domésticas reciben salarios inferiores al que perciben otras mujeres, se calcula que la viviendas y comida que se les proporciona representan aproximadamente $60 \%$ de sus salarios. Agradezco a la Profra. Julieta Quilodrán esta información. 
CUADRO 14

Porcentaje de trabajadoras según la clase de trabajadora, edad, escolaridad, estado civil, condición migratoria y tamaño de la familia, ciudad de México, 1970

\begin{tabular}{|c|c|c|c|}
\hline \multirow[b]{3}{*}{ Edad } & \multicolumn{3}{|c|}{ Clase de trabajadora } \\
\hline & \multicolumn{2}{|c|}{ Asalariada } & No asalariada \\
\hline & $\begin{array}{l}\text { Empleada } \\
\text { doméstica }\end{array}$ & Otros & Demás \\
\hline $20-24$ & $31.0 \%$ & $41.9 \%$ & $9.9 \%$ \\
\hline $25-29$ & 20.8 & 21.4 & 14.8 \\
\hline $30-34$ & 14.6 & 13.4 & 16.2 \\
\hline 35-39 & 13.3 & 9.8 & 17.6 \\
\hline $40-44$ & 12.8 & 7.5 & 17.6 \\
\hline $45-49$ & 7.5 & 6.0 & 23.9 \\
\hline Total & 100.0 & 100.0 & 100.0 \\
\hline Núm. de casos & $\{226\}$ & $(664)$ & $(142)$ \\
\hline \multicolumn{4}{|l|}{ Escolaridad } \\
\hline Ninguna & 37.6 & 3.3 & 11.4 \\
\hline \multicolumn{4}{|l|}{ Menor que } \\
\hline Primaria completa & 57.9 & 30.0 & 62.1 \\
\hline Primaria o más & 4.5 & 66.7 & 26.4 \\
\hline Total & 100.0 & 100.0 & 99.9 \\
\hline Núm. de casos & $(221)$ & $\{661)$ & $(140)$ \\
\hline \multicolumn{4}{|l|}{ Estado civil } \\
\hline Soltera & 41.6 & 56.6 & 12.8 \\
\hline Actualmente casada & 23.9 & 27.0 & 66.0 \\
\hline Anteriormente casada & 34.4 & 16.4 & 21.3 \\
\hline Total & 99.0 & 100.0 & 100.1 \\
\hline Núm. de casos & (219) & $(664)$ & $(141)$ \\
\hline \multicolumn{4}{|l|}{ Condición migratoria } \\
\hline Nativa & 28.5 & 73.1 & 51.4 \\
\hline Migrante origen rural & 64.7 & 18.9 & 37.7 \\
\hline Migrante origen urbano & 6.8 & 8.0 & 10.9 \\
\hline Total & 100.0 & 100.0 & 100.0 \\
\hline Núm. de casos & $(221)$ & $(650)$ & $(138)$ \\
\hline \multicolumn{4}{|l|}{ Tamaño de la familia } \\
\hline Ninguno & 42.8 & 59.0 & 17.7 \\
\hline 1 hijo & 13.5 & 12.1 & 8.5 \\
\hline $2-5$ hijos & 24.8 & 22.2 & 39.7 \\
\hline $6+$ hijos & 18.9 & 6.7 & 34.0 \\
\hline Total & 100.0 & 100.0 & 99.9 \\
\hline Núm. de casos & $(222)$ & $(654)$ & $(141)$ \\
\hline
\end{tabular}

Casos omitidos: edad $=0 ;$ escolaridad $=10 / 1032=1.0 \% ;$ estado civil $=1 / 1032 ;$ condición migratoria $=23 / 1032=2.2 \%$; tamaño de la familia $=15 / 1032=1.4 \%$. 
dad de las trabajadoras no asalariadas es sustancialmente mayor que la de las empleadas domésticas, pero bastante inferior a la de otras trabajadoras asalariadas. Asimismo, la proporción de trabajadoras no asalariadas nacidas en la ciudad de México se ubica entre la que corresponde a las empleadas domésticas y las demás trabajadoras asalariadas: $28.5 \%$ de empleadas domésticas, $73.1 \%$ de trabajadoras no asalariadas y $51.4 \%$ de otras trabajador as asalariadas. Las trabajadoras asalariadas, ya sean empleadas domésticas o de otro tipo, se concentran en las categorías de edad más bajas. ${ }^{16}$ Los resultados contradicen la idea de que el servicio doméstico es una ocupación exclusiva de las mujeres solteras jóvenes no comprometidas con responsabilidades familiares. Más de $50 \%$ de todas las empleadas domésticas están o fueron casadas y tienen al menos un hijo. No es sorprendente, que entre las mujeres que empezaron a trabajar antes de los 15 años, $41 \%$ sean empleadas domésticas comparadas con $34 \%$ de las no asalariadas y sólo $11 \%$ comprenden a las demás trabajadoras asalariadas. Además, confirmando que el empleo no asalariado constituye un nicho para las mujeres mayores casadas; $28 \%$ de las mujeres que empezaron a trabajar después de los 25 años son no asalariadas, comparadas con $10 \%$ de las iniciadoras tardías que son empleadas domésticas y $8 \%$ las demás trabajadoras no asalariadas.

\section{Conclusiones}

Esta investigación amplía las discusiones previas sobre la relación entre la industrialización y la estructura ocupacional en la ciudad de México al argumentar que, además de los factores relacionados con la demanda del trabajo, los determinantes de la condición salarial de las mujeres están condicionadas por restricciones individuales y familiares: la edad, la escolaridad, el estado civil, la condición migratoria, el tamaño de la familia, el género del jefe de familia, la estructura del hogar, el número de otros trabajadores en el hogar, y la presencia de niños pequeños, empleadas domésticas y personas mayores en el hogar. Las mujeres con mu-

${ }^{16}$ Los datos pueden conducir a conclusiones erróneas al sugerir que las asalariadas que no son empleadas domésticas son probablemente más jóvenes que las empleadas domésticas. No es posible hacer la comparación entre clases de trabajadoras menores de 20 años porque la muestra utilizada incluye únicamente mujeres entre los 20 y 49 años. Resulta razonable plantear la hipótesis de que una proporción significativamente más grande de las trabajadoras menores de 20 años son empleadas domésticas porque éstas tienen menor escolaridad y empiezan a trabajar en edades tempranas. 
chas responsabilidades domésticas tienen mayor probabilidad de ser no asalariadas porque este tipo de empleo permite una mayor flexibilidad en términos de horas de trabajo, ubicación del lugar de trabajo y cuidado de los niños.

El significado relativo de los factores individuales y familiares se determina de mejor forma articulándolos con la medición de la demanda de trabajo. Las pruebas de bondad de ajuste muestran que los modelos para la determinación del empleo asalariado que se basan únicamente en las características individuales y familiares de las trabajadoras no son muy poderosos. La investigación futura debería incluir la medición de la demanda de trabajo.

El estado civil, la edad, la escolaridad y dos variables próximas -la presencia de empleadas domésticas y personas mayores en el hogar- constituyen los principales determinantes individuales y familiares del empleo asalariado. El empleo no asalariado proporciona una oportunidad a las mujeres mayores casadas cuyas circunstancias económicas las obligan a generar un ingreso a pesar de la carga de sus responsabilidades domésticas. La magnitud del empleo no asalariado entre las mujeres casadas también refuta la evidencia previa de una baja participación en la fuerza de trabajo de las mujeres casadas.

Existe una heterogeneidad sustancial entre las categorías de condición salarial frente a los ingresos, la ocupación y los atributos del trabajo. No obstante, que la recompensa económica para la mayor parte del trabajo no asalariado es baja también lo es la remuneración percibida en muchas ocupaciones asalariadas. No resulta sorprendente encontrar, cuando se distingue el servicio doméstico de otras ocupaciones asalariadas, que existen claras diferencias entre las empleadas doméstiças, las demás trabajadoras asalariadas y las trabajadoras no asalariadas. El trabajo no asalariado refleja, en última instancia, consideraciones del ciclo de vida como la edad, el estado civil y el tamaño de la familia. Más que una opción, el empleo no asalariado surge como una estrategia económica, aunque inadecuada, para las mujeres cuya situación familiar les impide buscar empleos asalariados.

Es preciso comentar varias cuestiones metodológicas. Primero, los resultados señalan la necesidad de estudiar en forma independiente el cuidado de los niños y la suma de ingresos familiares como determinantes de la condición salarial. Las futuras investigaciones deberán combinar datos de encuesta y datos cualitativos y emprender el estudio de la articulación entre el cuidado de los niños y la realización de actividades no asalariadas específicas; la transformación del cuidado de los niños en utilización del trabajo infantil; y la manipulación del ingreso asalariado versus el no asa- 
lariado y la suma de ingresos familiares para justificar la desigualdad de edad y género dentro del hogar.

Segundo, los resultados indican que las estadísticas laborales convencionales subestiman la proporción de mujeres casadas que participan en la fuerza de trabajo. Muchas actividades femeninas no asalariadas están mal representadas. Debido a que algunas se realizan en el hogar o sin un lugar o local específico para el trabajo o porque algunas son clandestinas y no asalariadas, con frecuencia no se reporta su contribución económica al hogar. La evidencia indica que el empleo no asalariado constituye un importante nicho de actividad económica para las mujeres casadas.

Desde la óptima de la teoría social, no interpreto los resultados como un argumento del voluntarismo o una recomendación para que el Estado apoye la promoción de las actividades no asalariadas. Las mujeres casadas "prefieren" el trabajo no asalariado debido a razones estructurales a sociadas con aspectos tanto de la demanda como de la oferta. En términos de la oferta, la división del trabajo por género socialmente definida establece el trabajo doméstico como el rol principal de las mujeres casadas. Normativamente, sólo cuando las mujeres casadas aseguren la reproducción diaria de sus hogares, son libres para buscar maneras de complementar el ingreso del perceptor "principal". Su fundamentación económica se apoya en un amplio sistema de valores sociales y culturales y por el patriarcado. Cuando una mujer casada con pocas opciones para comprar u obtener de cualquier otra forma sustitútos para sus labores domésticas también debe trabajar, una de sus escasas opciones es el empleo no asalariado.

En términos de la demanda de trabajo, la estratificación de ocupaciones por género limita mucho la elección de trabajos disponibles. Debido a que las mujeres, y en particular las casadas, son percibidas por los patrones, esposos, familia y por la sociedad en general como trabajadores secundarios, se les ofrecen pocas oportunidades económicas en países con un excedente de mano de obra. Si el trabajo de las mujeres casadas fuese socialmente más aceptable, si la división del trabajo al interior del hogar fuese reestructurado de manera que aliviara a las mujeres de su doble responsabilidad y, si los empleos asalariados estuviesen disponibles, indudablemente las mujeres casadas "preferirían" ser asalariadas.

La visión retrospectiva nos dice que la importancia histórica de los patrones observados al principio de los setenta se fundamenta en el hecho de que cambios importantes en la economía mexicana estaban justamente a la vuelta de la esquina. En otra parte documento los cambios significativos en la distribución de las trabajadoras asalariadas y no asalariadas entre 1970-1976, el 
peor periodo de recesión económica en la historia de México hasta ese momento. El empleo no asalariado entre los hombres y mujeres en México también continuó creciendo durante los ochenta, una década todavía de crisis económica más profunda (Oliveira, 1989; García, 1988). Este incremento, que se presentó durante un periodo en el que se escenificaron obstáculos estructurales fundamentales para que continuase el crecimiento económico, es el tema de mi actual investigación.

\section{Apéndice}

Aclaraciones respecto a la construcción de las variables

Escolaridad:

La primaria completa significa 6 años de estudios.

Condición migratoria:

Nativas: mujeres que nacieron en la ciudad de México y continuaron viviendo ahí o mujeres nacidas en algún otro lugar que llegaron a la ciudad de México antes de los 13 años y permanecieron en ella.

Migrantes: mujeres nacidas en cualquier otro lugar que llegaron a la ciudad de México después de los doce años y permanecieron en ella y (o) mujeres nacidas en la ciudad de México que dejaron la ciudad siendo niñas y regresaron después de los 12 años.

Migrantes rurales: mujeres nacidas en áreas de menos de 20000 habitantes.

Migrantes urbanas: mujeres nacidas en áreas de 20000 habitantes y más. Para la regresión logística se construyeron variables dummy para las nativas y para las migrantes de origen rural y las de origen urbano.

\section{Estructura del hogar:}

Hogares compuestos: personas que viven solas y personas sin parentesco que viven juntas (no conyugalmente).

Hogares nucleares: una pareja sin hijos; una pareja con hijos solteros; madre soltera con hijos solteros. 
Hogares extendidos: una o más parejas y cualquier combinación de hijos, otros parientes y personas no emparentadas así como familias sin una unidad nuclear. Aquí se incluye cualquier combinación de hijos solteros y parientes o personas no emparentadas. Los hogares se agruparon en tres categorías: "nuclear", "extendido" y "otro", en donde "otro" combina hogares de personas que viven solas y de varias personas que viven juntas.

Trabajadores adicionales en el hogar:

La variable excluye al sujeto bajo estudio que trabajó del número total de trabajadores del hogar. Por ejemplo, si una mujer trabaja y no hay trabajadores adicionales en su hogar, la respuesta se codifica como cero (ningún trabajador adicional). Si una mujer trabaja y hay un trabajador adicional en su hogar, la respuesta es uno. La variable se trunca en el rango de 5 y más trabajadores adicionales.

\section{Bibliografía}

Alonso, José A. (1982), "Las trabajadoras a domicilio de la maquila del vestido en la metrópoli mexicana y sus relaciones con el capitalismo dependiente", en Estudios sobre la mujer: el empleo y la mujer. Bases teóricas, metodológicas y evidencia empírica, vol. 1, México, Secretaría de Programación y Presupuesto, Coordinación General de los Servicios Nacionales de Estadística, Geografía e Informática, Serie de Lecturas III, pp. 459-469.

Arizpe, Lourdes (1979), Las indígenas en la ciudad de México: el caso de las Marías, México, Diana, SepSetentas.

Barbieri, María Teresita de (1978), "Notas para el estudio del trabajo de las mujeres: el problema del trabajo doméstico", en Demografía y Economía, 12: 129-137.

(1984), "Incorporación de la mujer a la economía de América Latina", en Memorias del Congreso latinoamericano de Población y Desarrollo I, editado por G. Verduzco, México, unam, El Colegio de México, PISPAL, pp. 355-392.

Benería, Lourdes (1979), "Reproduction, Production and the Sexual Division of Labour", en Cambridge Iournal of Economics, 3: 203-225.

y Martha Roldán (1987), The Crossroads of Class and Gender: industrial Homework, Subcontracting and Household Dynamics in Mexico City, Chicago, University of Chicago Press.

Berger, Marguerite y Mayra Buvinic (eds.) (1988), La mujer en el sector informal, Quito, Ecuador, Nueva Sociedad.

Bunster, Ximena y Elsa M. Chaney (1989), Sellers ans Servants: Working Women in Lima, Peru, Granby, MA, Bergin y Garvey. 
Castells, Manuel y Alejandro Portes (1986), "World underneath: The Origin, Dynamics and Effects of the Informal Economy", ponencia presentada en la Conferencia para el Estudio Comparativo del Sector Informal, Harper's Ferry, Virginia, EUA.

Comisión Económica para Améria Latina y el Caribe (CEPAL) (1986), América Latina: Las mujeres y los cambios socio-ocupacionales, 19601980, LC/R.504, Santiago de Chile, CEPAL.

Elizaga, Juan Carlos (1968), Migración diferencial en algunas regiones y ciudades de la América Latina 1940-1950, serie A, núm. 8, Santiago de Chile, Centro Latinoamericano de Demografía.

Gailey, Christine Ward (1987), "Evolutionary Perspectives on Gender Hierarchy", en Analyzing Gender: A Handbook of Social Science Research, editado por B.B. Hess y M.M. Ferree, Newburry Park, Ca., publicaciones Sage, pp. 32-67.

García, Brígida (1988), Desarrollo económico y absorción de fuerza de trabajo en México 1950-1980, México, El Colegio de México. , Humberto Muñoz y Orlandina de Oliveira (1982), Hogares y trabajadores en la ciudad de México, México, El Colegio de México y UNAM.

Giner de los Ríos, Francisco (1984), "Proposal of a Typology to Analyze Very Small Enterprises and Results of its Application to Mexican Manufacturing", ponencia presentada en el Seminario sobre el Sector Informal en el Centro y la Periferia, Depto. de Sociología y el Programa de Historia Atlántica, Cultura y Sociedad, Baltimore, Johns Hopkins.

Hartmann, Heidi (1976), "Capitalism, Patriarchy and Job Segregation by Sex", en Blaxall y B. Reagan (eds.), Women and the Workplace: the Implications of Occupational Segregation, Chicago, University of Chicago Press, pp. 137-170.

Hass, Paula (1972), "Maternal Role Incompatibility and Fertility in Urban Latin America”, en lournal of Social issues, 26: 111-127.

Hosmer, David y Stanley Lemeshow (1989), Applied Logistic Regression, Nueva York, John Wiley.

Jelin, Elizabeth (1978), "La mujer en el mercado de trabajo urbano", vol. 1 (6), en Estudios CEDES.

Jusidman de Bialoztosky, Clara (1989), "Evolución del empleo y los mercados de trabajo en México," en Memorias de la Tercera Reunión sobre la Investigación Demográfica en México, vol. 1, México, Universidad Nacional Autónoma de México y Sociedad Mexicana de Demografía, pp. 513-530.

Lewis, W. Arthur (1959), The Theory of Economic Growth, Londres, Allen and Unwin.

Meillassoux, Claude (1981), Maidens, Meal and Money, Cambridge, Cambridge University Press.

Muñoz, Humberto y Orlandina de Oliveira (1977), "Oportunidades de empleo y diferencias de ingresos por sectores económicos", en $\mathrm{H}$. Muñoz, O. de Oliveira y C. Stern (eds.), Migración y desigualdad social en la ciudad de México, México, Instituto de Investigacio- 
nes Sociales de la Universidad Nacional Autónoma de México y El Colegio de México, pp. 141-156.

, Orlandina de Oliveira y Claudio Stern (eds.) (1977), Migración y desigualdad de México, México, Instituto de Investigaciones Sociales de la UNAM y el Colegio de México.

Oliveira, Orlandina de (1989), "Empleo femenino en México en tiempos de expansión y recesión económica: tendencias recientes", en Fuerza de trabajo femenina urbana en México 1, Características y tendencias, México, Coordinación de Humanidades de la UNAM y Miguel Ángel Porrúa, pp. 29-66.

y Humberto Muñoz (s.f.), Mexico City: Industrialization, Migration and the Labor Force, 1930-1970, Reporte Final, Nueva York, Division de Población, Consejo Económico y Social de las Naciones Unidas.

Pantelides, Edith Alejandra (1976), Estudio de la población femenina económicamente activa en América Latina, 1950-1970, Santiago de Chile, Centro Latinoamericano de Demografía.

Portes, Alejandro (1983), "The Informal Sector: Definition, Controversy and Relation to National Development", en Review (SUNY), 7: 151-174. (1985), "Latin American Class Structures: Their Composition and Change During the Last Decades", en Latin American Research Review, 20: 7-40.

y Laura Benton (1984), "Industrial development and labor absortion", en Population and Development Review, 10: 589-612.

Programa Regional de Empleo para América Latina y el Caribe (PREALC) (1981), Dinámica del subempleo en América Latina, Santiago de Chile, Organización Internacional del Trabajo.

(1982), Mercado de trabajo en cifras, 1950-1980, Santiago de Chile, Organización Internacional del Trabajo.

Rafferty, Adrián E. (1986), "Choosing Models for Cross-Classifications", en American Sociological Review, 51: 145-146.

Rendón, Teresa y Carlos Salas (1987), "Evolución del empleo en México, 1895-1980", en Estudios Demográficos y Urbanos, 2: 189-231.

Selby, Henry A., Arthur D. Murphy y Stephen A. Lorenzen (1990), The Mexican Urban Household: Organizing for Self-Defense, Austin, University of Texas Press.

Souza, Paulo Renato y Víctor Tokman (1975), El sector informal urbano, Santiago de Chile, Consejo Latinoamericano de Ciencias Sociales, Grupo de Trabajo sobre Ocupación y Desocupación.

Uchitelle, Louis (1990), "Untaxed Vendors Thrive in Mexico", en The New York Times, C: 2.

Youssef, Nadia (1974), Women and Work in Developing Societies, Westport, Conn., Greenwood Press. 